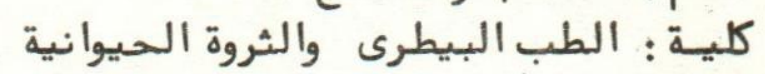

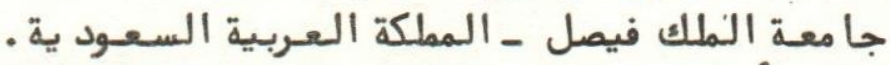

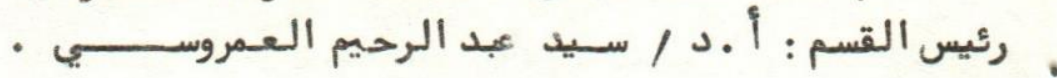

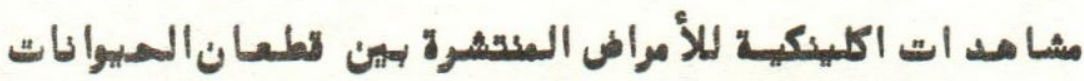

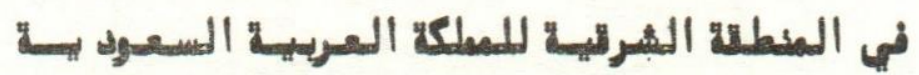

سيد العـمروسي ، مجدى ىحافظ ، نصر عاشور ، صلاح عبد الرازق ،رمضانعمر

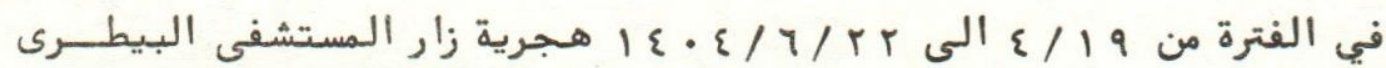

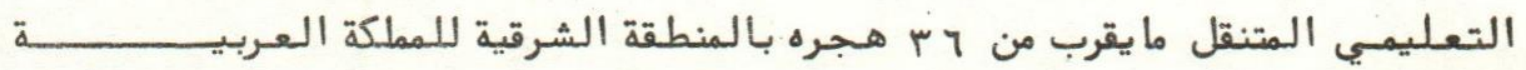

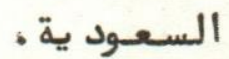

استهد فت الزيارة جمع بعض المعلومات والحقائق عن الأمراض التي انتشــربت

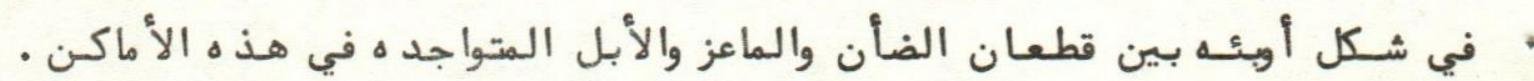

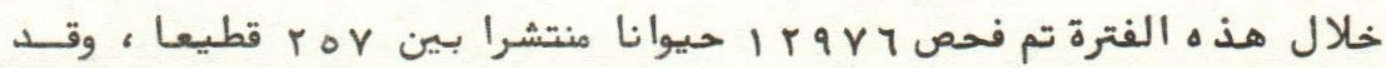

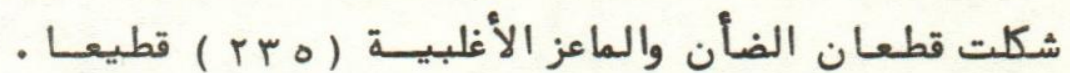

صاد فت الحملة العد يد من الحالات المرضيه مثل أمراض الجههاز التنفســي

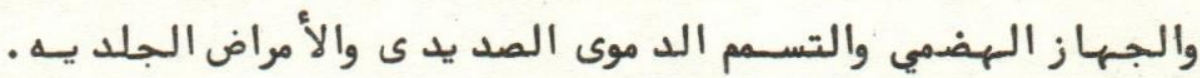


!

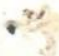

8 
Dept. of Med. \& Therap., Surgery \& Obst. and Pathology, College of Vet. Med. \& Animal Resoutces, King Faisal Univ., Saudi Arabia, Head of Dept. Prof. Dr. S. El-Amrousi.

\title{
OBSERVATIONS ON THE PREVALENT DISEASES AND SURGICAL AFFECTIONS OF LIVESTOCK IN THE EASTERN PROVINCE \\ OF SAUDI ARABIA \\ Part I: Common Herd Problems
}

\author{
By \\ S. EL-AMROUSI; A.M. HAFEZ; N.A. ASHOUR; S. ABDEL RAZIG \\ and R.O. RAMADAN \\ (Received at 21/6/1985)
}

\begin{abstract}
SUMMARY
During the period from 19.4.1404 to 22.6.1404 A.H. the mobile Clinic of the College of Veterinary Medicine and Animal Resources visited about 36 Higras distributed in the Eastern Province of the Kingdom.

The aim of the visit was to collect in collaboration with the Ministry of Agriculture and Water, some specific information about disease outbreaks in herds scattered in this province.

12,976 animals distributed on 257 herds were handled during this period, Sheep goat herds constituted the majority of these herds.

Various disease conditions involving either the respiratory or digestive systems were observed. Tick pyaemia and mange were also noted.
\end{abstract}

\section{INTRODUCTION}

The college of Veterinary Medicine and Animal Resources is continuously interested in investigating disease problems occuring in the animals within the Kingdom and in particularly the Eastern Province.

Furthermore, and in response to a directive from His Highness the Prince of Al-Hasa and in collaboration with the Directorate of Agriculture and Water in the Eastern Province, the Mobile Veterinary Clinic of King Faisal University embarked on immission aiming at the collection of some information about animal diseases in the area and adoption of appicable treatment and control measures.

\section{MATERIALS}

During the period from 19.4.1404 to 22.6.1404 A.H., the Mobile Clinic visited about 36 Higras(villages) distributed in the Eastern Province of the Kingdom. In these areas 12, 976 animals distributed on 257 herds were handled during this period. Sheep and goat herds constituted the majority (235 herds). Marked variations in management were noticed from herd to herd and in general there was considerable difficulty in determining the specific aetiology

Assiut Vet.Med.J. Vol. 15, No. 30, 1986. 


\section{S. EL-AMROUSI, et al.}

in different localities. It was also noticed that in the majority of herds, the investigated problems were due to more than one aetiological or predisposing foctor. This also applied for the various disease conditions involving either one system or more at one time. It is therefore more appropriate to discuss the conditions as a whole and this will be based mainly on the clinical signs on one hand and to some extent on the laboratory findings with the post-mortem lesions on the other.

\section{RESULTS and DISCUSSION}

\section{Respiratory Diseases}

About 1,646 cases distributed in nearly all the visited areas were suffering from pneumonias cased by different agents. The general picture varied probably due to the type and the virulence of the microorganism, thus making pneumonia in sheep and goats more than a single clinical entity. The incidence of infection in sheep reached an average of $25-35 \%$ in some herds.

General microbiological causes of pneumoria in sheep in the area of Al-Hasa, based on prior laboratory diagnosis at the Department of Microbiology included Mycoplasma ovipneumoniae, Pasteurella multocida, Escherichia coli, Staphyococci, Streptococci, Sphaerophorus necrophorus.

Difficulty in reaching a final diagnosis in the field was due to the lack of laboratory facilities on one hand and on the multiplicity of the suspected aetiological factors on the other. However, some specimens from diseased and freshly dead animals in one herd were examined and Pasteurella multocida was identified as the major cause.

Post-mortem findings of 32 cases supported the clinical evidence of pneumonic pasteurellosis. There were purulent foci in the lungs, red hepatization in some individuals and serofibrinous pleurisy in others. Puimonary congestion, oedema and heamorrhges on the serous surface of the thorax were also noticed. This simulates the macromorphological changes reported by SMITH, et al. (1972) and HAMDY and POUNDEN, (1959)

In our opinion, further investigations on pneumonia are necessary in sheep in the Kingdom because many possible causes are not fully investigated. The mycoplasmal and proliferative interstitial pneumonia, the virus pneumonia of sheep and sheep infleunza and others may be of paramount importance as some of the post-mortem findings consistent with such aetiological agents. Moreover, the first two types were suspected as the age of the severly affected animals was between ten weeks and six months old. Lambs of ten weeks age showed dry inspiratory râles and few of them showed clinical pneumonia. The main signs were moist coughing, sneezing and copious clear or mucoin nasal discharge. Owners observations indicated that coughing subsided and illness became le: severe in due course. However, after the elapse of about six months some lambs were sick again. It is known in this respect that mycoplasmal infection results in prolferative inters'. ial pneumonia which in the following weeks produces collapse, involving single or group of iobules (MERCHANT \& BARNER, 1975 and BLOOD, et al. 1982). This was clearly detected o; post-mortem finings of some carcasses having a generalized greyish colouration of their lung. The commonnest area affected was the right apical lobe of the lung together with the right and left cardiac lobes.

Treatment Ti:sls:

Se ral antibiotics mainly tylosin, oxytetracyclin, penicillin and streptomycin were used. Som: groups recieved sulphonamide therapy. Those cases which did'nt develop toxaemia responded ' s treatment, whereas others died.

Assiut Ve : Med.J. Vol. 15, No. 30, 1986. 


\section{DISEASES AND SURGICAL AFFECTIONS N SAUDI ARABIA}

\section{Digestive Discrders:}

Enterotoxaemia was suspected in 30 herds in which the history indicated that sheep and goats were apparently normal at night but found dead in the morning. Some individuals, however, showed progressive weakness, excitement, convulsions, excessive salivation, champing of the jaws, opisthotonus and died in convulsions. Confirmation of epsilon toxin type D Clostridium perfringens in the intestinal contents was not at hand during the work of the team. It is noteworthy that in this winter (1404) there was no or little rain in this area and consequently insufficient pasture to graze. The bedwins offered unlimitted amounts of barely and concentrates to their animals.

Other possible causes as haemorrhagic septicaemia and coccidiosis were excluded by laboratory investigation. Post-mortem lesions provided some evidence in some animals, however, although others showed no internal lesions. Active hyperaemia of kidneys, swollen dark red, petechiae, ecchymoses, were found occasionally in the peritonium, epicardium, endocardium, intestinal serosa, abdominal muscles and diaphragm. The simplest attempt towards controlling the disease was for the team to adopt reduction of the food intake and vaccination. It seemed that results of active immunization reached by Primovaccination* carried out by the authorities of the Ministry of Agriculture and Water in many. herds around the center of infected areas were (about $20 \mathrm{~km}$ ) satisfactory because further spread of the disease was not observed.

Tick Pyaemia:

Blood poisoning of newly born camels up to three months age occured in tick areas in the period between February and April when ticks are most active. Location of multiple abscesses in young camels (total number was 58 ageing from two months to one year) were mostly found on the region of the sternum, shoulders and in other parts of the body. The microorganisms were mainly Staphylococcus aureus which possibly gained entrance into the body through the tick bites; causing multiple abscesses in various part of the body. Abscesses were observed in the brain, liver and joint in two, five and two cases respectively. Similar findings could'nt be traced in the available literature. However, tick pyaemia in lambs develops a similar picture (SIEGMUND, et al. 1973).

\section{Skin Diseases:}

Mange caused by Psoroptes ovis was seen in skin scrapings from affected sheep. Lesions were observed on the head, around the ears, base of the horn, and infra-orbital fossa. However, in badly affected cases signs were most obvious on the sides and especially on the perineal and scrotal areas in rams. Ruggedness of the wool caused by scratching was also observed. The clinical picture was similar to that described by SOULSBY, (1977). In some areas there was a typical outbreak where many animals were affected and showed itching, emaciation and weakness. Wool contained large masses of scab which bound the fibers togather in a mat. In goats the picture was slightly different, and typical lesions were commonly found on the inside of ear \& lips. Some lesions on the outside and extending over the poll. In s $3 /$ erly affected cases the all legs were involved.

In camels typical lesions caused mainly by Sarcoptic scabiei var cameli apeared first on legs and around the tail, then gradually affected the neck and withers. In many sases lesions spread; affecting the rest of the body. Lesions caused intense itching and commenc: as papules usually overlooked by the bedwins, and enlarge peripherally and coalesce with iner lesions

* Imotoxan: Rhone merieux.

Assiut Vet.Med.J. Vol. 15, No. 30, 1986. 


\section{S. EL-AMROUSI, et al.}

so that very large areas of the skin were involved. The hair was lost, skin became thickened, wrinkled and covered with scabs. However, sometimes lesions may be small and alopecia may be present. Badly affected animals were weak and emaciated. A previous study on mange in camels was reported by HIGGINS, (1984); where Sarcoptic mange was the only mite of pathological importance.

Typical lesions of ringworm in camels were heavy white-grey crusts, sometimes clearly white but appeared grey due to dust. The lesions raised above the skin and appeared to be rough and about $3-7 \mathrm{~cm}$ in diameter. Lesions were commonly found on the neck, shoulders and sides. However, some cases with lesions over the entire body were also noticed. The lesions were extensive in young camels up to ten months old.

These clinical observations probably provide some guidlines for further and extensive investigations \& laboratory studies including isolation and identification of the various causative agents involved in many disease conditions in several species of domestic animals in the Eastern Province of the Kingdom of Saudi Arabia. The prelevance of such studies to disease control programmes can not be overemphasised.

\section{REFERENCES}

Blood, D.C.; Radostits, O.M. and Henderson, J.A. (1983): Veterinary Medicine 6th ed. Bailliere Tindall, London.

Hamdy, A.H. and Pounden, W.D. (1959): Experimental Production of Pneumonia In Lambs, Am. J. Vet. Res. 20: 78.

Merchent, I.A. and Barner, R.D. (1975): An Outline of the Infectious Diseases of Domestic Animals, 3rd ed., lowa State Univ. Press, lowa, U.S.A.

Siegmund, O.H. (1973): The Merck Vetrinary Manual 4th ed. Merck \& Co. Inc. Rahway, N.J., U.S.A.

Smith, H.H.; Jones, T.C. and Hunt, R.D. (1972): Veterinary Pathology, 4th ed. Lea \& Febiger, Philadelphia.

Soulsby, E.J.L. (1977): Helminths, Arthropods \& Protozoa of Domesticated Animals, 6th ed. Baillere Tindall, London. 